\title{
STATIC STRENGTH OF SQUARE TUBULAR Y-JOINTS WITH REINFORCED CHORD UNDER AXIAL COMPRESSION
}

\author{
Y. Chen ${ }^{1}$ and Y.B. Shao ${ }^{2, *}$ \\ ${ }^{1}$ Graduate student, China Ministry of Education Key Laboratory of Building Safety and Energy \\ Efficiency, College of Civil Engineering, Hunan University, Changsha, China \\ ${ }^{2}$ Professor, School of Mechatronic Engineering, Southwest Petroleum University, Chengdu, China \\ *(Corresponding author: E-mail: cybshao2009@hotmail.com)
}

Received: 26 June 2012; Revised: 9 September 2012; Accepted: 9 October 2012

\begin{abstract}
Chord reinforcement is an available alternative to improve the static strength of the welded square tubular joints. Four full-scaled square tubular Y-joints are studied experimentally to investigate the effect of local chord reinforcement on their static strength. From experimental results, it is found that the static strength of a square tubular Y-joint can be improved greatly by increasing the chord thickness locally near the brace/chord intersection. The failure mode of an un-reinforced Y-joint can be changed from local yielding around the brace/chord intersection to flexural yielding of the chord member when the local chord thickness is increased to a critical value. In addition, finite element (FE) models for analyzing the static behavior of square tubular Y-joints are also presented, and the accuracy and reliability of these models have been evaluated by comparing the FE results with experimental results. Finally, influence of some parameters $\left(L_{\mathrm{c}} / d, \beta, \gamma\right.$ and $\left.T_{\mathrm{c}} / t_{0}\right)$ on the static strength of square tubular Y-joints with local chord reinforcement is studied, and a parametric equation for predicting the static strength of square tubular Y-joints with local chord reinforcement under axial compression is presented. The accuracy of the presented equation is verified through error analysis.
\end{abstract}

Keywords: Square tubular T-joints, chord reinforcement, finite element, static strength, parametric equation

DOI:10.18057/IJASC.2016.12.3.1

\section{INTRODUCTION}

The static strength of welded steel tubular joints is of considerable importance, both in the design stage and during servicing time. One of the primary design concerns for steel tubular structures is the static strength of the connection between different tubular members (namely tubular joint). As high stress concentration exists at the weld toe, failure generally occurs on the chord surface around the weld. For a tubular joint, the brace members are mainly subjected to axial loads, and thus the chord is frequently subjected to the load in its radial direction. Due to the hollow section, the radial stiffness of the chord is much smaller than the axial stiffness of the brace. If the static strength of a joint is found to be inadequate, various methods are available to reinforce it. The most commonly used reinforcements in tubular structures, such as doubler-plate, collar-plate, internally stiffened ring and infilled concrete, have been reported in the literature.

The fatigue behavior of internally ring-stiffened welded steel tubular joints was investigated by Gandhi et al. [1], who created an extensive database on internally ring-stiffened steel tubular joints, and experimental investigations on internally ring-stiffened steel tubular joints with different geometries were conducted under various loading conditions and environments. Van der Vegte et al. [2] studied the static strength of Y-joints reinforced with doubler- or collar-plates by using both numerical and experimental methods, and the numerically and experimentally determined load-ovalization curves reveal a very good correlation. The results show that a significant strength enhancement can be achieved through proportioning the doubler-plate. Lee and Llewelyn-Parry [3] conducted a detailed parametric study on the static strength of axially loaded tubular T-joints with internal ring-stiffeners, and they carried out nonlinear finite element analyses to evaluate the 
accuracy and the validity of the numerical procedure through comparison with tested results in other literature. Nazari et al. [4] presented parametric equations for predicting the stress concentration factors (SCF) for tubular T-, Y-, K-, X-, and DT-joints reinforced with doubler-plate, and a sensitivity analysis is performed for describing the effect of joint types on the SCF stress concentration factors. The numerical study of doubler-plate stiffened CHS T- and X-joints subjected to in-plane bending was carried out by Choo et al. [5] to investigate the failure modes and the load transferring mechanisms of such joints with different sizes of doubler-plate, and the design recommendations were presented for the doubler-plate reinforced X-joints. The hysteretic behavior of circular tubular T-joint reinforced with collar-plate under quasi-static cyclic loading was studied experimentally by Shao et al. [6]. Through experimental observation, the failure position was found to be transferred from the weld toe along the brace/chord intersection to the corner of the collar-plate, and therefore the reinforced circular tubular T-joints can dissipate more energy and have better ductility. Gao et al. [7] carried out experimental study on concrete-filled steel tubular arches with corrugated steel webs. It was found that the infilled concrete can improve the local and global buckling of the steel tube, and the static strength of the joint is then increased efficiently.

As a novel and innovative reinforcing measure, local chord reinforcement is an alternative in improving the static strength of tubular joints. The significant effectiveness of this reinforcing method has been studied by Shao et al. [8]-[9]. This method remedies the defect that a doubler- or a collar-plate cannot be used for multi-planar tubular joints with several brace members connecting to the chord, and it does not influence the joint appearance. This reinforcing method has been applied in engineering practice such as Guangdong Science Center in China. However, it is still necessary to conduct further study on the reinforcing efficiency of this method for design purpose.

This study then aims to carry out detailed investigation to propose convenient yet accurate estimation on the static strength of a square tubular Y-joint with local chord reinforcement under axial compression. The overall research program involves both experimental tests and finite element (FE) studies. Through verifying the reliability of the FE model against the experiments described, an extensive parametric analysis is conducted, and finally a parametric equation is presented to be possibly used in practical design stage.

\section{EXPERIMENTAL TEST}

\subsection{Specimen Details}

Generally, a tubular joint is consisted of two or more hollow section tubes. The large through member is called chord, and the other branch members are called braces which are welded directly onto the chord surface. Figure 1 shows the fabrication of a square tubular Y-joint, in which the brace end is profiled firstly, and then it is welded onto the chord surface directly by using full penetration welds. Because welding process can produce uneven temperature distribution around the brace/chord intersection, it is carried out on-site after installation to avoid large residual deformation.

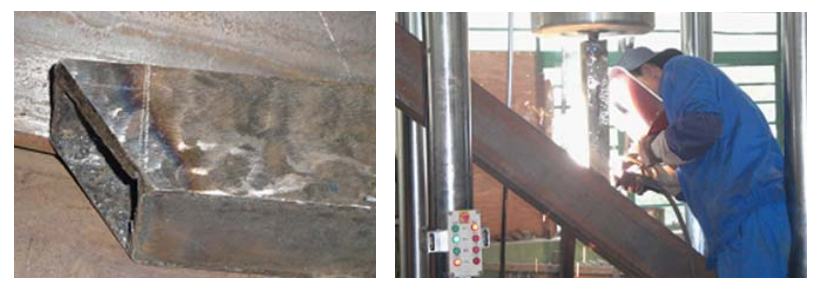

Figure 1. Fabrication of A Square Tubular Y-joint 
The schematic arrangement of a square tubular Y-joint specimen is illustrated in Figure 2. The chord is strengthened near the brace/chord intersection by increasing the tube thickness locally, and the outer width of reinforced tube is same to that of the un-reinforced tube to keep the outer surface of the two tubes are coplanar. The locally reinforced segment is connected to the un-reinforced one by using butt weld in which a gradient of 1:2.5 is used to connect the different tube thicknesses. The reinforcing efficiency of this method can be controlled by varying the thickness $T_{\mathrm{c}}$ and the length $L_{\mathrm{c}}$ of the enhanced segment. The joint is considered not to be reinforced when $T_{\mathrm{c}}=t_{0}$ and $L_{\mathrm{c}}$ $=L_{0}$. The geometries of all the specimens used in the experimental tests are summarized in Table 1 . The specimens include two reinforced models and two corresponding un-reinforced ones. The reinforced square tubular Y-joints have same dimensions as the un-reinforced specimens except that the chord of the reinforced segment has a larger value of thickness and length. The chord and the brace of each square tubular Y-joint specimen are fabricated by seamed carbon steel pipe while the reinforced segment is obtained by welding four steel plates together. It is noted that the reinforced segment can be also fabricated by rolling a steel plate into a square tube when the thickness of the reinforced tube is not quite big and the fabrication is easily processed. However, four steel plates are suggested to be welded together when such thickness is quite big due to easy fabrication. When four steel plates are welded together to form a square tube, the welding side of each steel plate is also profiled to be a slope, and partial but weld is used to connect two adjacent plates together. Both chord ends are welded onto a steel plate, and each plate is welded two ear plates pinned to the supports to produce hinged boundary conditions at the chord ends.

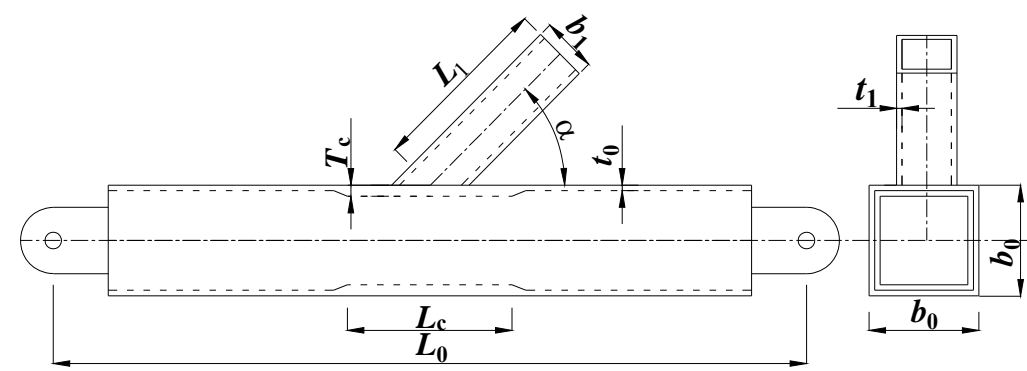

Figure 2. A Chord Reinforced Y-joint

Table 1. Geometry of Specimens

\begin{tabular}{|c|c|c|c|c|c|c|c|c|c|c|c|}
\hline NO. & $\begin{array}{c}b_{0} \\
(\mathrm{~mm})\end{array}$ & $\begin{array}{c}b_{1} \\
(\mathrm{~mm})\end{array}$ & $\begin{array}{c}t_{0} \\
(\mathrm{~mm})\end{array}$ & $\begin{array}{c}t_{1} \\
(\mathrm{~mm})\end{array}$ & $\begin{array}{c}L_{0} \\
(\mathrm{~mm})\end{array}$ & $\begin{array}{c}L_{1} \\
(\mathrm{~mm})\end{array}$ & $\begin{array}{c}L_{\mathrm{c}} \\
(\mathrm{mm})\end{array}$ & $\begin{array}{c}T_{\mathrm{c}} \\
(\mathrm{mm})\end{array}$ & $\beta$ & $2 \gamma$ & $\alpha\left(^{\circ}\right)$ \\
\hline Ex-1 & 180 & 70 & 8 & 8 & 2437 & 467 & - & - & 0.389 & 22.5 & 50.5 \\
\hline Ex-2 & 180 & 70 & 8 & 8 & 2437 & 467 & 200 & 16 & 0.389 & 22.5 & 50.5 \\
\hline Ex-3 & 160 & 100 & 8 & 8 & 1959 & 550 & - & - & 0.625 & 20.0 & 74.5 \\
\hline Ex-4 & 160 & 100 & 8 & 8 & 1959 & 550 & 200 & 16 & 0.625 & 20.0 & 74.5 \\
\hline
\end{tabular}

The specimens are made up of Q235 steel which is widely used in steel structures in China. A uni-axial tensile test is conducted to measure the mechanical properties of the steel materials, such as steel yield stress, tensile stress, elastic modulus and elongation percentage. The measured results are listed in Table 2. The coupons used in the uni-axial tensile tests are shown in Figure 3. The steel materials of the pipes used in the square tubular Y-joint specimens have good plasticity as shown in Figure 4, in which the experimentally measured stress-strain curves are plotted. The material properties of the reinforced segments are obtained from the manufacturers. 

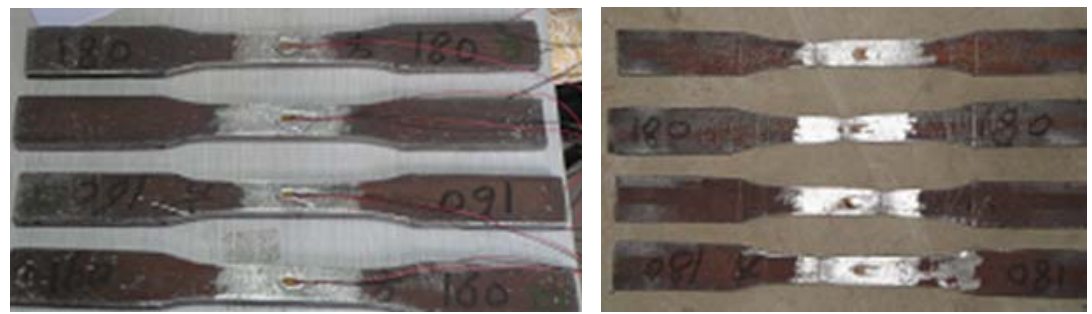

Figure 3. The Standard Coupon Test

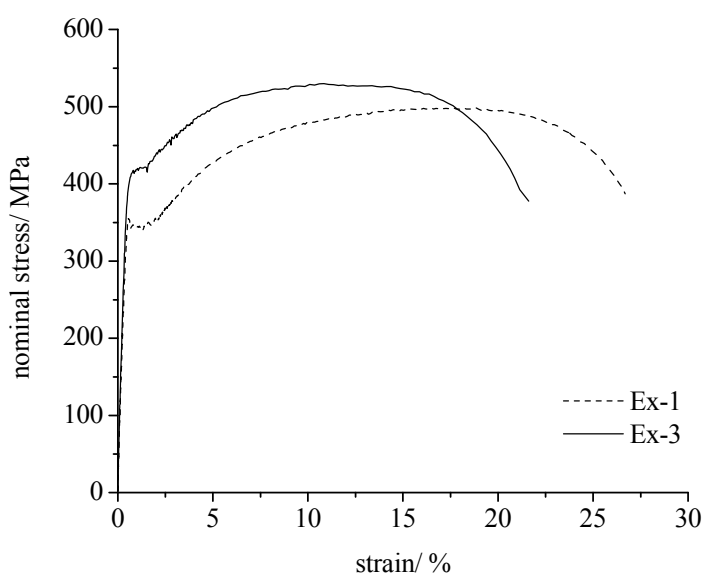

Figure 4. Stress-Strain Curves

Table 2. Material Properties

\begin{tabular}{|c|c|c|c|}
\hline NO. & $\begin{array}{c}\text { Yield stress } \\
\left(\mathrm{N} / \mathrm{mm}^{2}\right)\end{array}$ & $\begin{array}{c}\text { Ultimate stress } \\
\left(\mathrm{N} / \mathrm{mm}^{2}\right)\end{array}$ & Elongation (\%) \\
\hline EX-1 & 340 & 499 & 26 \\
\hline EX-2 & 348 & 527 & 22 \\
\hline EX-3 & 415 & 529 & 22 \\
\hline EX-4 & 417 & 529 & 23 \\
\hline Reinforced segment & 280 & 455 & 26 \\
\hline
\end{tabular}

\section{$2.2 \quad$ Test Setup}

All experimental tests are conducted in a test rig as shown in Figure 5. The test rig has a maximum loading capacity of $500 \mathrm{kN}$, and the maximum magnitude of the axial displacement is $\pm 75 \mathrm{~mm}$. The test rig has a special data acquisition system which can collect and export real-time applied load and the axial displacement at the brace end. During the experimental test, the specimens are pinned at both ends of the chord, and the load is applied at the brace end in axial direction.

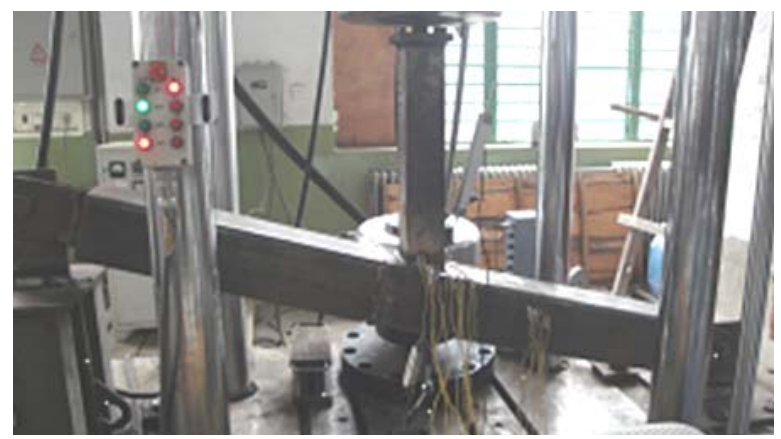

Figure 5. Test Setup 
During the tests on the un-reinforced specimens, LVDTs are placed on both the upper and lower surface of the chord at the brace/chord intersection, as shown in Figure 6(a), to measure the deformation of the chord in transverse direction. However, for the reinforced specimens, LVDTs are placed on a location near the chord intersection which is the maximum deformation position and is estimated from finite element analysis, as shown in Figure 6(b).

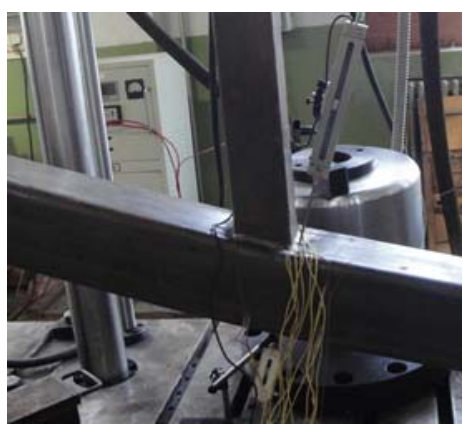

(a) Un-reinforced Joints

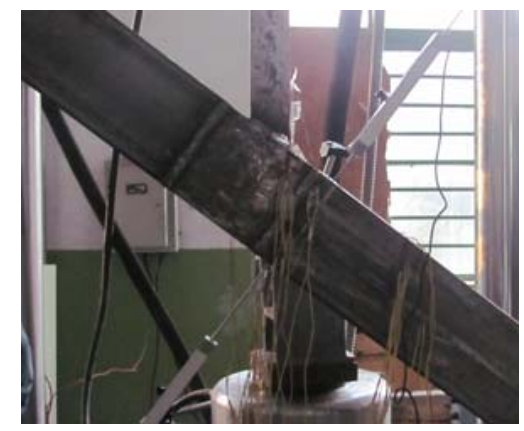

(b) Reinforced Joints

Figure 6. Arrangement of LVDTs

\subsection{Loading Scheme}

In the elastic stage, loading is controlled gradually at a speed of $10 \mathrm{kN} / \mathrm{min}$. The loading control is changed to displacement control at a speed of $0.5 \mathrm{~mm} / \mathrm{min}$ when a critical point in the load-displacement curve initiates and nonlinear stage begins. Displacement control is used in this stage because a large deformation may occur even though only a small loading increment is applied. During the tests, the applied loads and the axial displacement at the brace end can be both recorded automatically from the data acquisition system. The deformation of the joint can be measured from the LVDTs.

\section{FINITE ELEMENT ANALYSIS}

\subsection{Finite Element Modeling}

The numerical study is carried out from non-linear finite element analysis by using software ANSYS. 20-node hexahedral element is used to model the entire structure. In the vicinity of the brace/chord intersection, a refined mesh is used to simulate a high stress gradient, and a relatively coarse mesh is used in the regions far away from the intersection to save computing time. Although residual stress exists at the weld of the brace/chord intersection, the distribution of the residual stress along the weld is very complicated because it is affected by welding sequence, welding method, techniques of welders and so on. It is difficult to put all the situations into consideration. Fortunately, previous study shows the ignorance of the weld in analyzing the static strength of a tubular joint can still produce accurate enough results. In addition, omission of the weld produces underestimation for the radial stiffness of the chord, and thus the calculated result of the static strength is conservative. Based on these considerations, Weld is not considered in the FE model. Figure 7 shows the detailed FE mesh of both an un-reinforced square tubular Y-joint and a chord reinforced one. 


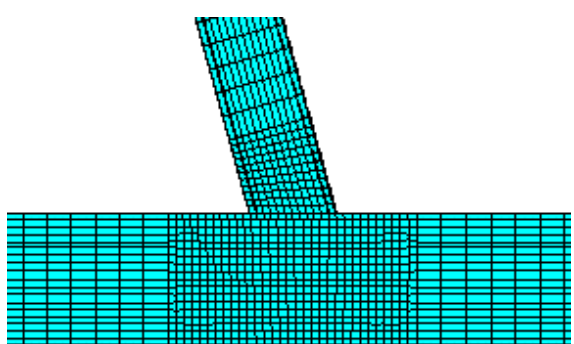

(a) Un-reinforced Y-joint

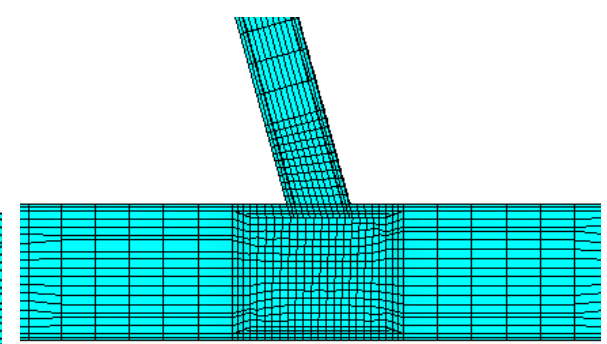

(b) reinforced Y-joint

Figure 7. FE Meshes of Square Tubular Y-joints

\subsection{Boundary Conditions and Material Properties}

In the FE models, loading is applied to the center of the steel plate at the brace end. To simulate an actual boundary condition in the experimental tests, pins are set to be at both ends of the chord, as shown in Figure 8(a). However, one end is released to be a roller in following parametric study, as shown in Figure 8(b). Pin-roller constraints are set to the chord ends to avoid axial tensile stresses in the chord because such stresses can increase the static strength of the Y-joint. This treatment is safe and reasonable for estimating the static strength of a tubular joint since it is impossible to acquire accurate information on the exact level of the axial stress in the chord.

In the following parametric study, the steel material has a yielding stress of $235 \mathrm{~N} / \mathrm{mm}^{2}$ and a Poisson's ratio of 0.3 . However, the experimental results are obtained based on the experimentally measured material properties as listed in Table 2.

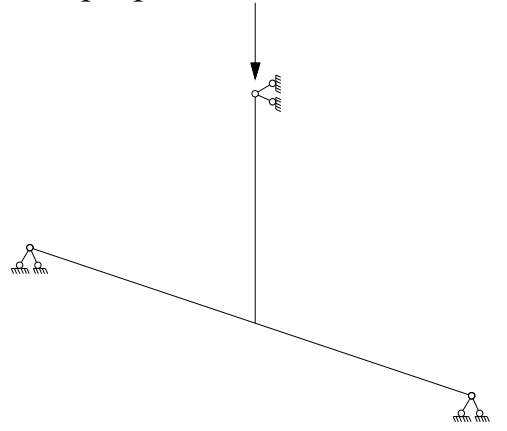

(a) Validation Study

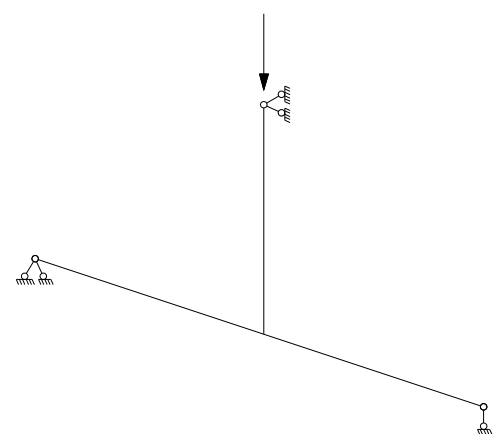

(b) Parametric Study

Figure 8. Boundary Conditions

\subsection{Convergence and Validation Studies}

Although the FE model can be benchmarked from experimental results, it must be evaluated from convergence study firstly. The convergence study is conducted by comparing the results obtained from FE models with different mesh densities because the FE results will converge to a fixed value if the mesh density is high enough. In the convergence study, two tested Y-joint specimens, including an un-stiffened one and a stiffened one, are analyzed with various mesh layouts and densities. The details are tabulated in Table 3 and Table 4.

As seen from Table 3, the ultimate load of the un-reinforced model or the reinforced model tends to be a fixed value when the mesh density increases gradually in the FE analyses. The results are more accurate with the increase of the mesh density. The results in Table 4 show that there is only a difference of $2 \%$ in the ultimate load between models EX-4-3 and EX-4-1, even though the mesh density of EX-4-3 is 9.5 times greater than that of EX-4-1. It indicates that accurate result can be 
obtained by using the mesh density of EX-4-1 or EX-4-2. As a result, an approximate element size in the regions around the brace/chord intersection and around the chord/chord intersection can be determined to guarantee the convergence of the FE results.

Table 3. Convergence Study for Un-stiffened Joint EX-3

\begin{tabular}{|c|c|c|}
\hline $\begin{array}{c}\text { Mesh } \\
\text { reference }\end{array}$ & $\begin{array}{c}\text { Number of } \\
\text { elements }\end{array}$ & $\begin{array}{c}\text { Ultimate load } \\
(\mathrm{kN})\end{array}$ \\
\hline EX-3-1 & 2283 & 251.82 \\
\hline EX-3-2 & 3745 & 245.59 \\
\hline EX-3-3 & 4805 & 242.83 \\
\hline EX-3-4 & 6781 & 239.17 \\
\hline EX-3-5 & 8594 & 237.20 \\
\hline
\end{tabular}

Table 4. Convergence Study for Stiffened Joint EX-4

\begin{tabular}{|c|c|c|}
\hline Mesh reference & $\begin{array}{c}\text { Number of elements in } \\
\text { reinforced chord }\end{array}$ & Ultimate load $(\mathrm{kN})$ \\
\hline EX-4-1 & 616 & 291.01 \\
\hline EX-4-2 & 916 & 289.65 \\
\hline EX-4-3 & 5939 & 284.13 \\
\hline
\end{tabular}

After the cost-effective mesh layout is determined, numerical models of two further joints are analyzed to validate the FE procedure. The results of the validation study are shown in Table 5. The definitions of the static strength of the joints are classified into three types: the maximum axial force at the brace end, the axial force at the brace end with a defined deformation limit and the axial force at the brace end obtained from the twice-elastic-slope (TES) method [10]. Figure 9 shows the definition on the TES. The above three definitions on the static strength are dependent on the load-displacement/deformation curves. When there is a clear loading drop after the linear stage in the load-displacement curve, the peak load is taken as the static strength of the joint. However, the peak load cannot be located from the load-displacement/ deformation curve if there is no loading drop in the curve. In this case, the second (deformation limit) or the third definition (TES) will be used to locate the static strength of the joint.

The difference between the deformation limit and the TES is determined from the local deformation of the chord around the brace/chord intersection. For example, there is clear local deformation in this position for the un-reinforced square tubular Y-joint because the transverse stiffness of the chord is smaller than the axial stiffness of the brace. For a square tubular Y-joint with $0.6 \leq \beta \leq 0.8$, the load at a joint deformation of $3 \% b_{0}$ is defined as the static strength of this joint (Zhao [11]), and it is easily obtained from the load-deformation curve. It is different for the Y-joint with local chord reinforcement because the joint deformation may be much smaller. Due to the increased chord thickness around the brace/chord intersection, the transverse stiffness of the chord in this region is improved greatly. TES method is then used for this situation. In Figure 9, the static strength of a tubular joint is determined from a point with an angle $\varphi$ in the load-displacement curve. The value of $\varphi$ is determined from the following relationship: $\tan \varphi=2 \tan \theta$. As the tested results of all specimens befit the TES method, they are obtained based on this method. 
Table 5. Validation Study

\begin{tabular}{|c|c|c|c|}
\hline \multirow{2}{*}{ Model } & \multicolumn{3}{|c|}{ Ultimate load $(\mathrm{kN})$} \\
\cline { 2 - 4 } & Test & FE & Test/FE \\
\hline EX-1 & 171.75 & 160.27 & 1.07 \\
\hline EX-2 & 289.44 & 280.05 & 1.03 \\
\hline EX-3 & 230.01 & 228.64 & 1.01 \\
\hline EX-4 & 261.26 & 282.60 & 0.92 \\
\hline
\end{tabular}

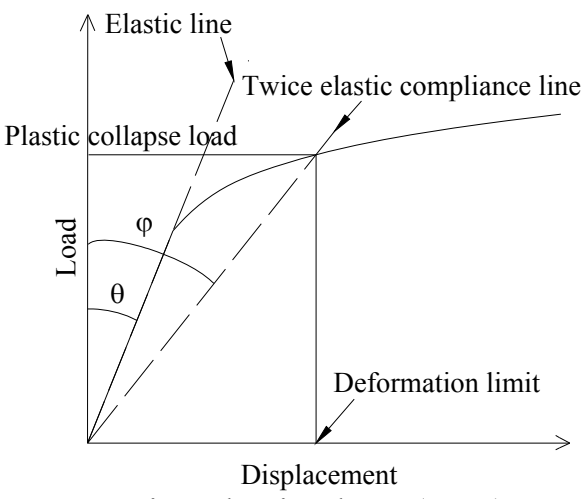

Figure 9. Twice-elastic-slope (TES) Method

According to the above three definitions, the static strength of the analyzed models in Table 5 can be obtained both from experimental tests and from FE analyses. Table 5 shows the comparison between the two results. The agreement shows reasonably well as the maximum relative error is only $8 \%$. To evaluate the accuracy of the FE model in more details, the load-displacement curves of the un-stiffened Y-joints and the Y-joints stiffened with chord reinforcement obtained from both FE analyses and experimental measurements are plotted together in Figure 10.

It is found that the FE and the experimental results of the stiffness in the linear stage of the load-displacement curves are some different. However, the results of the static strength between the two methods are much closer. The stiffness in the linear stage obtained from the FE analyses is always bigger than that obtained from experimental measurements. Such difference is caused by the actual pinned constraints at the ends of the chord in experimental tests. To simulate a pinned constraint, the chord is hinged at both ends by inserting a pin into a drilled hole in the end plate. As the hole diameter is a little bigger than the diameter of the pin, there is a sliding shift between the hole and the pin. For the FE analyses, the pinned constraint at the chord end is only implemented by restricting the freedoms of a node of the end plate in three directions, and such modeling cannot reflect the actual sliding in experimental tests. Due to the above reason, the stiffness of the load-displacement curve in the linear stage of the experimental results is smaller. However, such difference does not affect the static strength significantly. 


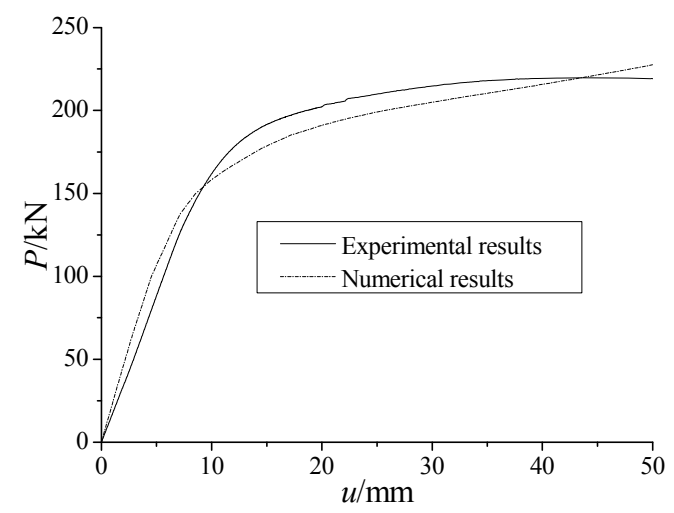

(a) Ex-1

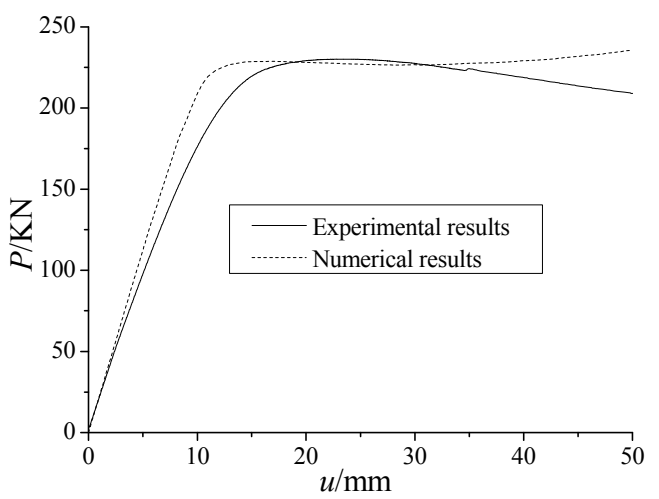

(c) Ex-3

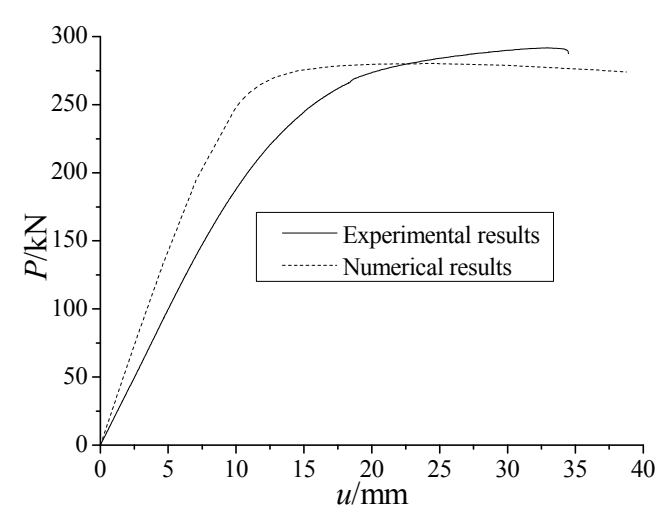

(b) Ex-2

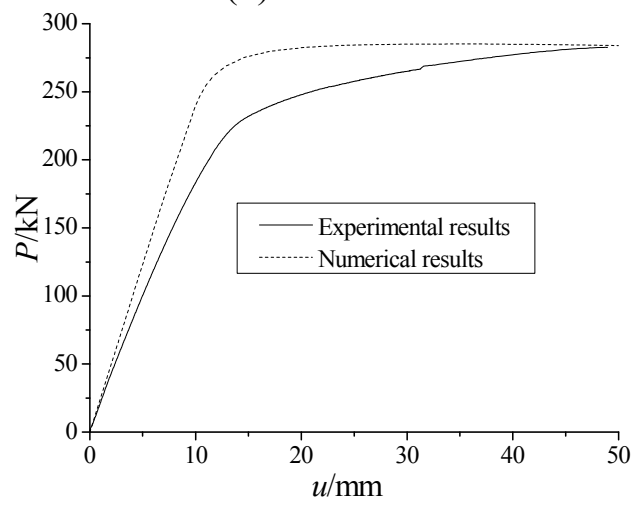

(d) Ex-4

Figure 10. Load-Displacement Curves of the Y-joint Specimens

\subsection{Failure Mode}

The good correlation between the experimental and the numerical results can also be illustrated by the deformed shapes at failure as shown in Figure 11. The equivalent failure mode obtained from FE calculations indicates that the presented FE model can predict the final failure mode of both the un-reinforced and the reinforced tubular Y-joints reliably. From experimental tests and FE analyses, it can be found that the failure mode of a tubular Y-joint may be changed if suitable chord reinforcement is taken. When the local chord thickness near the brace/chord intersection is increased properly, the chord stiffness in transverse direction can be improved efficiently. As can be seen from Figures 11(a) and 11(c), there is clear concaved deformation around the weld toe for the un-reinforced Y-joint specimens, which indicates that the un-reinforced specimens fail due to local yielding. However, if the local radial stiffness of the chord near the weld is improved enough by increasing the local chord thickness, the failure location may move to the chord/chord intersection as shown in Figures 11(b) and 11(d). In this situation, the chord behaves much like a bending beam, and the final failure is caused by the flexural yielding on the top and on the bottom surfaces at the chord/chord intersection. 

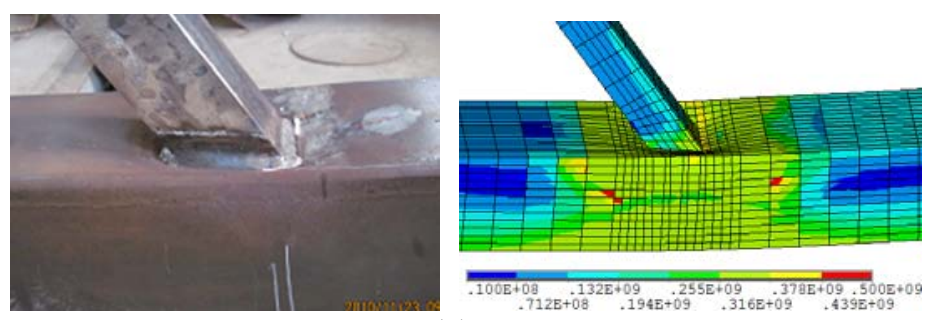

(a) Ex-1
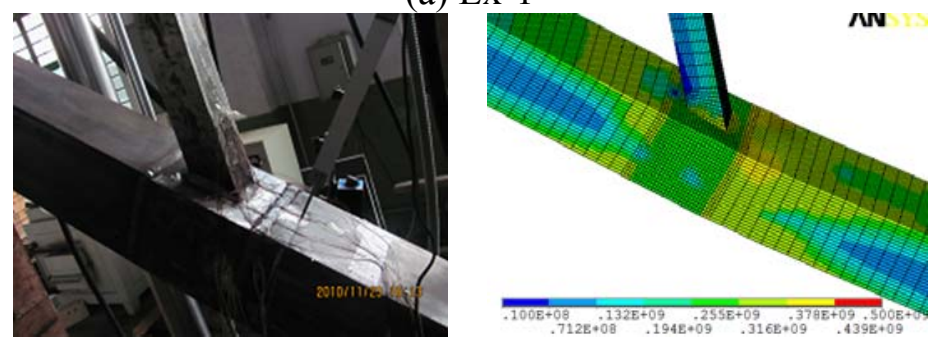

(b) $\mathrm{Ex}-2$
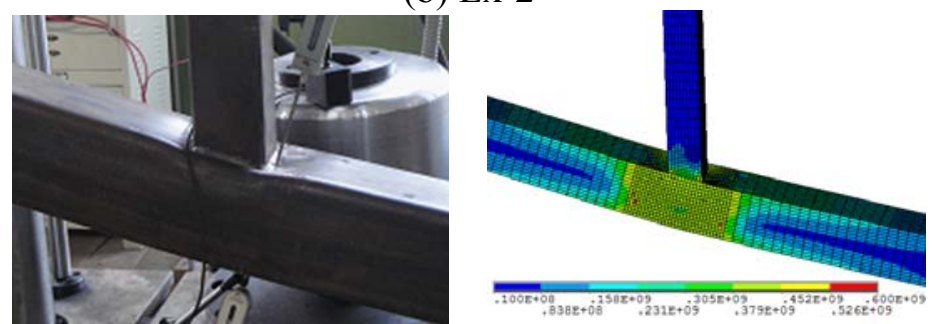

(c) $\mathrm{Ex}-3$
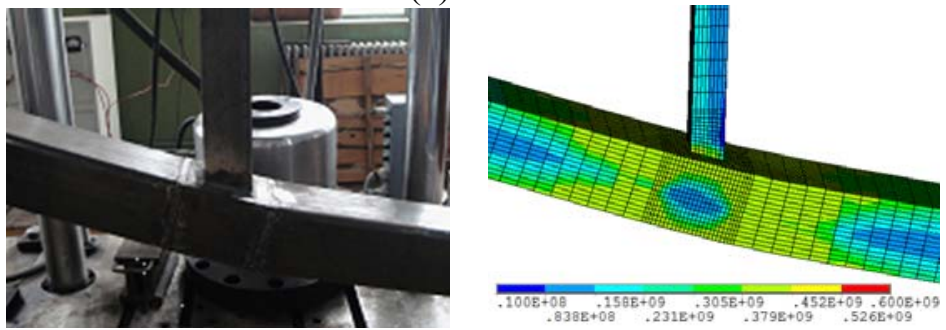

(d) Ex-4

Figure 11. Failure Modes

\section{PARAMETRIC STUDY}

Although the static strength of a square tubular Y-joint can be improved efficiently by increasing the local chord thickness near the brace/chord intersection as mentioned previously, the reinforcing efficiency must be studied from a parametric investigation. The parameters considered in numerically parametric study include the following ones: (1) chord width to wall thickness ratio $2 \gamma$; (2) brace to chord width ratio $\beta$; (3) the reinforced to the un-reinforced chord thickness ratio $T_{\mathrm{c}} / t_{0}$; (4) the intersecting angle $\alpha$ between the chord and the brace. Table 6 shows the detailed values of the above parameters in the FE analyses.

Table 6. Parameter Values

\begin{tabular}{|c|c|c|c|}
\hline$B$ & $\gamma$ & $\alpha$ & $T_{\mathrm{c}} / t_{0}$ \\
\hline $0.4,0.6,0.8$ & $6,8,10,12$ & $30,45,60,75$ & $1.25,1.5,1.75,2.0$ \\
\hline
\end{tabular}


In the parametric study, overall 102 square tubular Y-joint models with a validity range of the parameters tabulated in Table 6 are analyzed. Based on the FE results, the efficiency of the chord reinforcement is then investigated.

\subsection{Effect of Chord Reinforced Length}

From the parametric study, it has been found that the effect of $L_{\mathrm{c}} / b$ ( $b$ is the length of the brace intersected on the chord surface) on the reinforcing efficiency is much ineffective than the effect of $T_{\mathrm{c}} / t_{0}$ as seen in Figure 12. Although Figure 12 only shows the effect of the chord reinforcement of a single typical Y-joint, it represents the general pattern. As $L \mathrm{c} / b$ has little influence on the static strength of a square tubular Y-joint, it is not necessary to increase the reinforced chord length considerably in practical design. The applicable value of this parameter can be taken based on the consideration of easy construction, especially the effect of the welding process on the residual deformation. Due to this reason, the value of $L_{\mathrm{c}} / b$ is taken with $L_{\mathrm{c}} / b=2$ in parametric study.

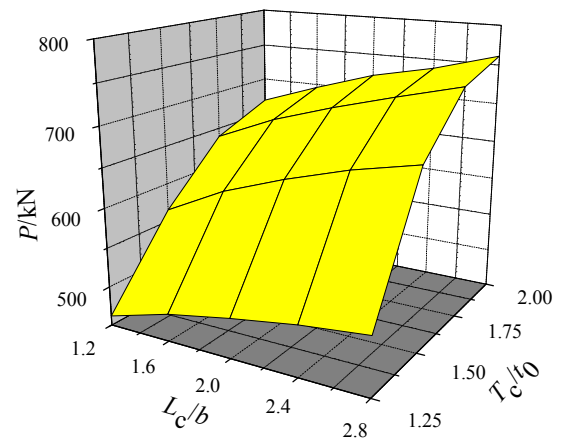

Figure 12. Efficiency of Chord Thickness Reinforcement

\subsection{Effect of Other Parameters}

From the results of the parametric study, the effects of the prescribed 4 parameters on the static strength of a chord reinforced square tubular Y-joint $(P)$ under axial compression are obtained, and they are plotted in Figure 13. Some conclusions can be generalized based on the results in Figure 13 as follows: (1) It is significantly effective to improve the static strength of a square tubular Y-joint by increasing the local chord thickness. However, such effective improvement only exists when the $T_{\mathrm{c}} / t_{0}$ is less than a critical value, i.e. $T_{\mathrm{c}} / t_{0} \leq 1.5$ for the models shown in Figure 13(a). Beyond this value, $T_{\mathrm{c}} / t_{0}$ has a little influence. This phenomenon can be explained from the failure mechanism of the tubular Y-joint which will be introduced in the following section in details. (2) The effect of parameter $\beta$ on the static strength of a square tubular Y-joint presents basically a linear relationship as illustrated in Figure 13(b). (3) The relationship between $P$ and $\gamma$ changes from nonlinearity into linearity with the increase of the reinforced chord thickness, which can be seen in Figure 13(c). (4) The effect of $\alpha$ on the static strength can be seen in Figure 13(d), which shows that $P$ reduces greatly with the increase of $\alpha$.

\subsection{Failure Mechanism}

Based on the parametric investigation, it can be found that a very small increment of the chord thickness near the brace/chord intersection can significantly improve the static strength of square tubular Y-joints when $\beta$ is relatively small. As $\beta$ represents the width ratio of the brace to the chord, a smaller value of $\beta$ means the width of the brace is much smaller than the chord's width. Hence, the contact area of the brace/chord intersection is small in this situation. When the Y-joint is subjected to brace axial loading, such smaller contact area causes high stress around the intersection, and the joint then fails much easily. The typical failure mode of the un-reinforced 
square tubular Y-joint is shown in Figure 14(a) and 14(c). The hollow section of the chord causes the chord stiffness in transverse direction to be much smaller than the brace stiffness in axial direction. As the chord has to sustain the load in transverse direction when the brace is subjected to axial loading, failure generally occurs on the chord surface around the weld toe. Definitely, increasing the local chord thickness near the weld toe can improve the chord stiffness in transverse direction significantly, especially when $\beta$ has a small value.

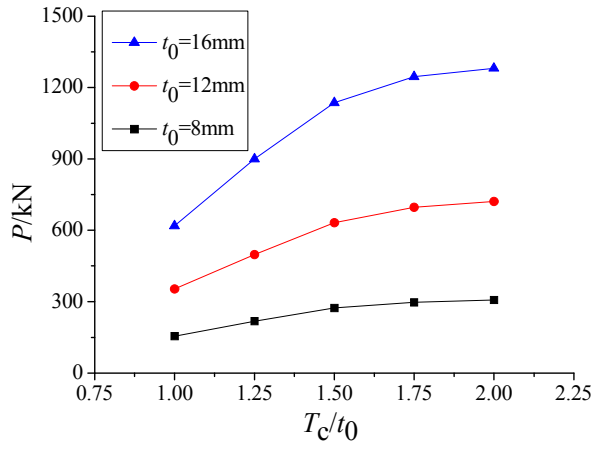

(a) Effect of $T_{\mathrm{c}} / t_{0}(\beta=0.4, \gamma=12)$

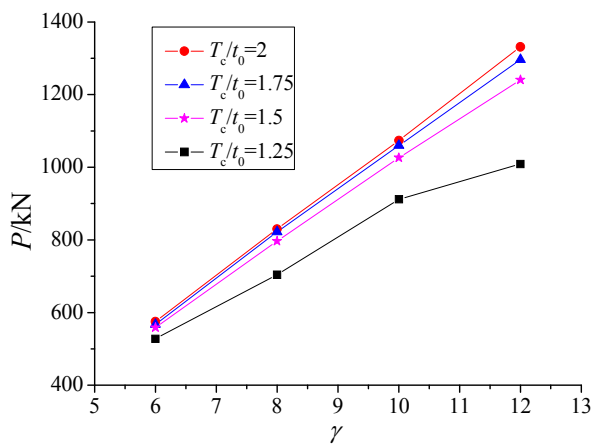

(c) Effect of $\gamma\left(t_{0}=12, \beta=0.4\right)$

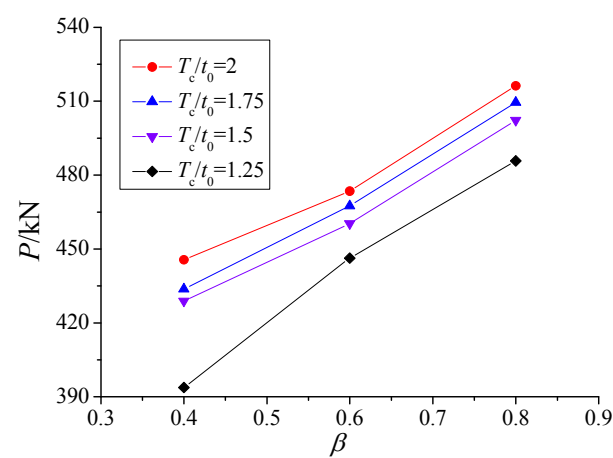

(b) Effect of $\beta\left(t_{0}=12, \gamma=8\right)$

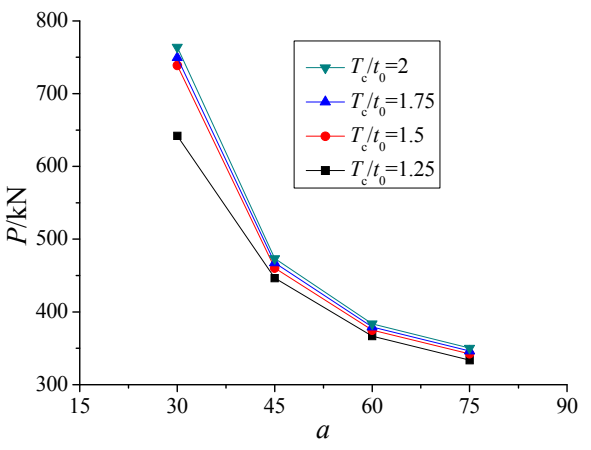

(d) Effect of $\alpha(\gamma=8, \beta=0.6)$

Figure 13. Effect of Parameters on Static Strength

Similarly, it is more effective to improve the static strength of a square tubular Y-joint when the value of $\gamma$ is much bigger. $\gamma$ is the ratio of the chord width to the chord thickness of the un-reinforced joint. A bigger value of $\gamma$ means a thin-walled chord. When the chord thickness is small, the chord stiffness in transverse direction must be very weak, and the static strength of the joint is then very low. In overall, increasing the chord thickness locally near the weld toe is much effective when the chord thickness is much smaller.

The improvement of the static strength of a square tubular Y-joint can be explained in details by analyzing the failure mechanism of a reinforced model. As seen from Figure 14(b) and 14(d), the failure mechanism of a square tubular Y-joint with reinforcement is much different when the local chord thickness is increased to a certain value. If the local chord is reinforced enough, the chord stiffness in transverse direction can exceed the brace stiffness in axial direction. At this time, it is ineffective to improve the static strength by continuing to increase the local chord thickness, which is proved in Figure 13(a). Such ineffectiveness can be also explained from Figure 14(b) and 14(d). Due to the over-strengthening of the local chord near the brace/chord intersection, the reinforced chord has enough transverse stiffness, and then the failure location moves to the chord/chord intersection. In this case, the chord behaves much like a flexural beam, and failure of the joint now 
is caused due to large flexural deformation. When the chord is hinged at both ends, the chord can be taken as a simply supported beam. The failure mechanism of the square tubular Y-joint is now explained as chord flexural failure.

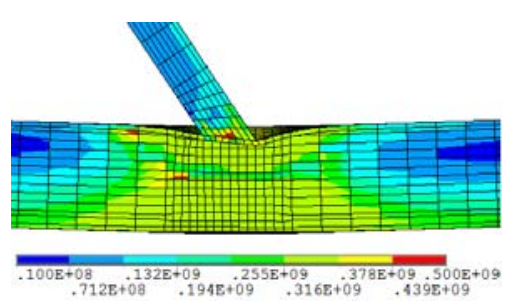

(a) Ex-1

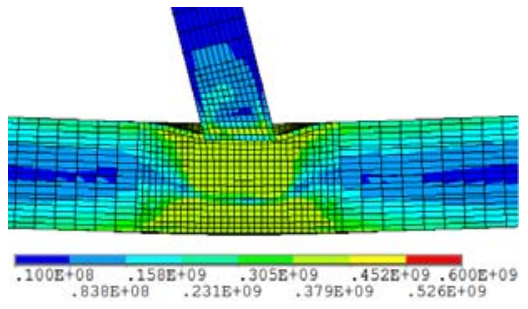

(c) Ex-3

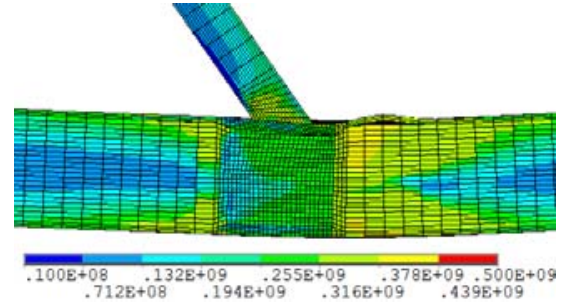

(b) $\mathrm{Ex}-2$

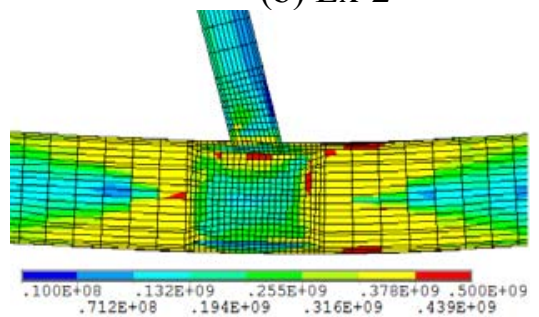

(d) Ex-4

Figure 14. Deformed Shapes of Both Stiffened and Un-stiffened Y-joint Models

\section{PARAMETRIC EQUATION FOR PREDICTING STATIC STRENGTHS OF A Y-JOINT}

Based on the above parametric study, a parametric equation for predicting the static strength of a square tubular Y-joint under axial compression $\left(P_{\mathrm{c}}\right)$ is proposed. The equation is developed by examining the influence of the different sizes of reinforcement and various geometric parameters. Curve fitting technique and regression analysis are used to obtain the following parametric equation

$$
P_{c}=\left\{0.021 \beta_{c} \gamma_{c}\left(\alpha^{0.051}+0.174\right)\left[1-\left(T_{c} / t_{0}\right)^{-1.907}\right]+1\right\} P_{0}
$$

where $P_{0}$ is the static strength of the un-reinforced square tubular $\mathrm{Y}$-joint, which can be found in many design guidelines such as CIDECT [12]. The unit of the intersecting angle $\alpha$ is in radian. Other geometric parameters in Eq. (1) are listed as follows:

$$
\begin{aligned}
& \beta_{c}=0.171-0.134 \beta \\
& \gamma_{c}=\gamma^{2.51}+42.18
\end{aligned}
$$

It is specified here that the value of $T_{\mathrm{c}} / t_{0}$ is taken to be 1.5 when such value is greater than 1.5 in Eq. (1), which can be found from Fig. 13(a) that the reinforcing efficiency is very minor when $T_{\mathrm{c}} / t_{0}$ is greater than 1.5 .

To verify the accuracy of Eq. (1), a comparison between the predicted results and the FE results is conducted, and the evaluation can be given from Figure 15. $P_{\mathrm{f}}$ and $P_{\mathrm{c}}$ are the results of FE simulation and the equation's prediction respectively. From the comparison, the FE results have reasonable agreement with the predicted results, which implies that Eq. (1) has good accuracy and reliability. 


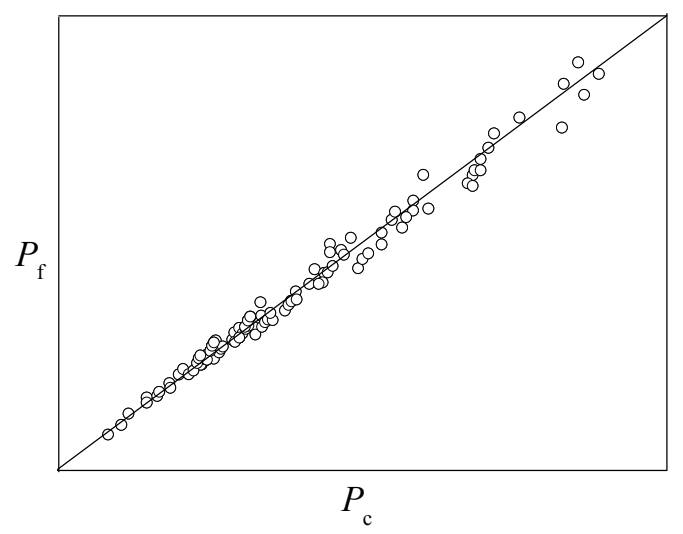

Figure 15. Comparing of Predicted and FE Results

The accuracy of Eq. (1) can be also assessed from error analyses. The relative error $e_{\mathrm{i}}{ }^{*}$, the averaged relative error $e$, the relative standard variance $s^{*}$ and the relative average standard variance $s$ are defined and listed as follows:

$e_{i}^{*}=\frac{P_{f i}-P_{c i}}{P_{f i}} \quad(i=1,2,3 \ldots n)$

$e=\frac{\sum_{i=1}^{n}\left|e_{i}^{*}\right|}{n}$

$s^{*}=\sqrt{\frac{\sum_{i=1}^{n}\left|e_{i}^{*}\right|^{2}}{n-1}}$

$S=\sqrt{\frac{\sum_{i=1}^{n}\left(\left|e_{i}^{*}\right|-e\right)^{2}}{n-1}}$

$P_{\mathrm{fi}}$ and $P_{\mathrm{ci}}$ are the results of FE simulation and equation's prediction respectively. The total number of the models is $n$. The values of $e, s^{*}, s$ are calculated to be $5.54 \%, 6.79 \%, 6.41 \%$ respectively. Such small error values can also prove the accuracy of Eq. 1 in estimating the static strength of a square tubular Y-joint with chord reinforcement.

Using Eq. a, the static strengths of the reinforced specimens Ex-2 and Ex-4 can be also calculated, and the results are $326 \mathrm{kN}$ and $226 \mathrm{kN}$ respectively. Compared to the experimental results, i.e., $289.4 \mathrm{kN}$ and $261.3 \mathrm{kN}$, the relatively errors are $12.8 \%$ and $-13.4 \%$, which indicates that the estimation is acceptable.

As Eq. 1 is obtained based on the above parametric study, it has to be satisfied with a validity range. This range is listed as follows: $0.4 \leq \beta \leq 0.8,6 \leq \gamma \leq 12,1 \leq T_{\mathrm{c}} / t_{0} \leq 1.5$ (when $T_{\mathrm{c}} / t_{0}>1.5$, its value is taken to be 1.5 in Eq. (1)), $30^{\circ} \leq \alpha \leq 75^{\circ}$. 


\section{CONCLUSIONS}

Experimental tests and FE analyses have both proved that the static strength of a square tubular Y-joint can be improved effectively by increasing the local chord thickness near the brace/chord intersection. Based on a parametric study, the effect of some parameters including $\beta, \gamma, T_{\mathrm{c}} / t_{0}$, $\alpha$, and $L_{\mathrm{c}} / b$ on improving the static strength is carried out. Finally, a parametric for predicting the static strength is presented. Generally, the following conclusions can be obtained:

(1) There is a remarkable improvement on the static strength of a square tubular Y-joint under axial compression with reinforced chord. However, $T_{\mathrm{c}} / t_{0}$ should not exceed a certain value (it is advised to be not larger than 1.5) otherwise there is ineffective improvement.

(2) It is ineffective to increase the static strength of a square tubular Y-joint under axial compression by increasing the length of the reinforced chord segment.

(3) The proposed parametric equation can provide accurate and reliable prediction on the static strength of a chord reinforced square tubular Y-joint in a validity range of joint geometry.

\section{REFERENCES}

[1] Ganhi, P., Raghava, G. and Ramachandra Murthy, D.S., "Fatigue Behavior of Internally Ring-stiffened Welded Steel Tubular Joints", Journal of structural engineering, 2000, Vol. 126, No. 7, pp. 809-815.

[2] Van der Vegte, G.J., Choo, Y.S., Liang, J.X., Zettlemoyer, N., Liew, J.Y.R., "Static Strength of T-joints Reinforced with Doubler or Collar Plates, II: Numerical Simulations", Journal of Structural Engineering, ASCE, 2005, Vol. 131, No.1, pp. 129-138.

[3] Lee, M.M.K., and Llewelyn-Parry, A., "Strength of Ring-stiffened Tubular T-joints in Offshore Structures-A Numerical Parametric Study", Journal of Constructional Steel Research, 1999, Vol. 51, pp. 239-264.

[4] Nazari, A. Guan, Z., Daniel, W.J.T., Gurgenci, H., "Parametric Study of Hot Spot Stresses around Yubular Joints with Doubler Plates", Practice Periodical on Structural Design and Construction, ASCE, 2007, Vol. 12, No.1, pp. 38-47.

[5] Choo, Y.S., Liang, J.X., Van der Vegte, G.J., Liew, J.Y.R., "Static Strength of Doubler Plate Reinforced CHS X-joints Loaded by in-plane Bending”, Journal of Constructional Steel Research, 2004, Vol. 60, pp. 1725-1744.

[6] Shao, Y.B., Yue, Y.S., and Cai, Y.Q., "Experimental Study on Hysteretic Behavior of Circular Tubular T-joints Reinforced with Collar-plate", Engineering Mechanics, 2011, Vol. 28, No.10, pp. 209-215.

[7] Gao, J., Su, J.Z., Xia, Y., Chen, B.C., "Experimental Study of Concrete-filled Steel Tubular Arches with Corrugated Steel Webs", Advanced Steel Construction, 2014, Vol. 10, No. 1, pp. 99-115.

[8] Shao, Y.B., Li, T., Seng, T. L., Chiew S.P., "Hysteretic Behavior of Square Tubular T-joints with Chord Reinforcement under Axial Cyclic Loading", Journal of Constructional Steel Research, 2011, Vol. 67, No.1, pp. 140-149.

[9] Shao, Y.B., Lie, S.T., and Chiew S.P., "Static Strength of Tubular T-joints with Reinforced Chord under Axial Compression", Advances in Structural Engineering, 2010, Vol. 13 No.2, pp. 369-377.

[10] Moffat, D.G., Hsieh, M.F., and Lynch, M., "An Assessment of ASME III and CEN TC54 Methods of Determining Plastic and Limit Loads for Pressure System Components", Journal of Strain Analysis, 2001, Vol. 36 No. 3, pp. 301-312. 
[11] Zhao, X.L., "Deformation Limit and Ultimate Strength of Welded T-joints in Cold-formed RHS Sections", Journal of Constructional Steel Research, 2000, Vol. 53, pp. 149-165.

[12] CIDECT, "Design Guide 3: For Rectangular Hollow Section (RHS) Joints under Predominantly Static Loading”, Second Edition. 2009. 